\title{
Aplikasi Pupuk SP-36 dan Ekstrak Pelarut Fosfat untuk Meningkatkan Produksi Jagung Lokal Pulut
}

\section{The Application of SP-36 Fertilizer and Phosphate Solvent Extraction for Improvement of Local Waxy Corn Production}

\author{
Edy $^{1^{*}}$, Taufan Alam ${ }^{2}$, Baktiar ${ }^{1)}$ \\ 1) Fakultas Pertanian, Universitas Muslim Indonesia, Makassar \\ 2) Fakultas Pertanian, Universitas Gadjah Mada, Yogyakarta \\ *) Penulis untuk koresponden Email: nuhungedy63@yahoo.com
}

\begin{abstract}
Imports of rice every year increasing with increasing number of Indonesian population. Based on this, the necessary diversification of staple food rice equivalent is developing corn fluffier rice products. The research objective was to increase production of waxy corn and efficient fertilization of phosphorus. The research is designed in a randomized complete block design (RCBD) factorial with three replications. The first factor was application of banana weevil extract: without extract and the extract (10 L.ha $\left.{ }^{-1}\right)$. The second factor was $P$ fertilizer consisting of 0, 50, 100 and $150 \mathrm{~kg}^{-h^{-1}}$ SP-36. The data was analyzed used ANOVA $\alpha=5 \%$ and continued by DMRT $\alpha=5 \%$. The results

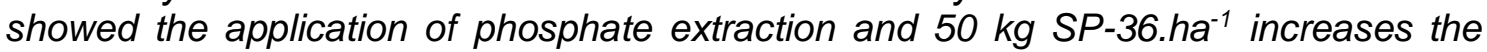
length and diameter of the cob, and production of seed per hectare, SP-36 fertilization more efficient and quality taste and fluffier.
\end{abstract}

Keywords: rice, waxy corn, phosphate solvent extraction

\section{INTISARI}

Impor beras setiap tahun semakin meningkat seiring meningkatnya jumlah penduduk Indonesia. Berdasarkan hal tersebut, diperlukan diversifikasi pangan pokok yang setara beras yaitu mengembangkan produk beras jagung pulen. Tujuan penelitian adalah meningkatkan produksi jagung pulut dan efisiensi pemupukan fosfat. Penelitian menggunakan rancangan acak kelompok (RAK) faktorial dan diulang sebanyak tiga ulangan. Faktor I adalah aplikasi ekstrak pelarut fosfat (EPF) yang bersumber dari bonggol pisang yang terdiri atas 0 dan 10 liter.ha $^{-1}$. Faktor kedua adalah pemupukan SP-36 yaitu 0, 50, 100 dan $150 \mathrm{~kg} \cdot \mathrm{ha}^{-1}$. Analisis data menggunakan ANOVA $\alpha=5 \%$ dan dilanjutkan uji DMRT $\alpha=5 \%$. Hasil penelitian menunjukkan aplikasi EPF dan 50 kg.ha-1 SP-36 meningkatkan panjang dan diameter tongkol, dan produksi biji kering per hektar serta efisiensi pemupukan $P$.

Kata kunci: beras jagung, jagung pulut, ekstrak pelarut fosfat 


\section{PENDAHULUAN}

Impor beras setiap tahun semakin meningkat seiring meningkatnya jumlah penduduk Indonesia, oleh karena itu pengembangan pertanian pangan masih merupakan sektor yang sangat penting, sehingga tetap menjadi salah satu prioritas untuk mendukung program utama lainnya. Peningkatan produksi jagung termasuk jagung lokal pulut perlu tetap mendapat perhatian dengan memanfaatkan potensi sumberdaya alam yang tersedia. Produksi jagung lokal pulut selama ini kurang maksimal karena berbagai hal antara lain, pengelolaan yang asalan karena hanya sebagai tanaman selingan, dan relatif tidak dikomersilkan. Jagung lokal pulut mempunyai banyak kelebihan dibandingkan jagung kuning sehingga dapat menjadi bahan makanan alternatif pengganti beras untuk mendukung program ketahanan pangan.

Budidaya jagung pulut juga dibutuhkan pupuk sebagai sumber unsur hara yang sangat diperlukan dan perlu diperhatikan agar produksi jagung lokal pulut bisa maksimal, namun tingginya harga pupuk di pasaran membuat para petani enggan menggunakan pupuk sesuai rekomendasi. Oleh karena itu perlu mengefisienkan pupuk yang diberikan agar terurai dan tersedia secara maksimal bagi tanaman dan dilain pihak biaya pupuk bisa dikurangi. Aplikasi pupuk terutama pupuk $P$ umumnya tidak semua terserap oleh tanaman, sebagian terikat dalam tanah oleh $\mathrm{Al}$ dan $\mathrm{Fe}$ (Hardjowigeno, 1992). Oleh karena itu perlu upaya agar $P$ yang terikat di dalam tanah tersebut terlepas agar dapat digunakan oleh tanaman. Hasil penelitian menunjukkan bahwa ekstrak bonggol dan batang pisang mengandung mikroorganisme pelarut fosfor (Pratamaningtyas, 2011), namun penelitian ini masih tingkat laboratorium sehingga perlu dilanjutkan di lapangan. Berdasarkan hal tersebut di atas maka perlu diuji di lapangan dengan berbagai kombinasi perlakuan agar diperoleh hasil jagung lokal pulut yang optimal dan berkualitas sehingga dapat dibuat beras jagung pulen bergizi.

Salah satu indikator menurunnya produktifitas lahan adalah tidak efektifnya pemupukan. Penambahan dosis pupuk yang dimaksudkan untuk meningkatkan produksi tidak dapat memberikan hasil seperti yang diharapkan. Pupuk yang diberikan ke lahan tidak semua larut dalam tanah sebagian terikat oleh Fe dan Al menyebabkan pemupukan P tidak efisien (Hardjowigeno, 1992). Hasil penelitian yang dilakukan oleh Pratamaningtyas (2011) menemukan bahwa pada bonggol dan batang pisang terdapat mikroorganisme pelarut fosfat. Isolasi, identifikasi dan uji kemampuan melarutkan 
fosfat oleh mikroorganisme yang dikandung bonggol dan batang pisang ditemukan satu isolat yang mempunyai kemampuan kuat dan cepat dalam melarutkan fosfat yaitu isolat-1 adalah Serratia marcescens dengan kemampuan melarutkan $P$ secara kuantitatif adalah $357 \mathrm{mg} / \mathrm{L}$.

Menurut Ohio State University Extension (2010) dalam Rouf (2010), jagung pulut (waxy corn) adalah jagung yang memiliki 100\% amilopektin sedangkan jagung normal mengandung amilopektin $75 \%$ dan $25 \%$ amilosa. Jagung pulut merupakan jagung lokal yang terdapat dibeberapa daerah di Indonesia dan dikonsumsi sebagai jagung rebus, kue, jagung bakar, dan mulai dikembangkan beras jagung instan karena bergizi, rasanya enak dan gurih, namun potensi hasilnya sangat rendah kurang dari 2 ton/ha, sangat peka terhadap penyakit bulai (Perenosclerospora maydis L.), tetapi toleran terhadap cekaman kekeringan (Makkulawu dkk., 2012). Penelitian ini bertujuan untuk meningkatkan produksi jagung lokal pulut, mengefisienkan pemupukan $P$, dan menciptakan beras jagung pulen berkualitas.

\section{BAHAN DAN METODE PENELITIAN}

Penelitian dilaksanakan di lahan kering Makassar Sulawesi Selatan. Maret-Juli 2017. Penelitian didesain dalam rancangan acak kelompok (RAK) faktorial dua factor yang diulang sebanyak tiga ulangan. Faktor pertama adalah dosis ekstrak pelarut fosfat (EPF) yang bersumber dari bonggol pisang yaitu tanpa 0 dan 10 liter.ha-1. Faktor kedua adalah pemupukan SP-36 (P) yaitu 0, 50, 100 dan 150 kg.ha-1. Parameter penelitian meliputi panjang dan diameter tongkol, bobot $100 \mathrm{biji}$, bobot biji per hektar serta efisiensi penggunaan P. Analisis data menggunakan ANOVA $\alpha=5 \%$ dan jika menunjukkan perbedaan nyata dilajutkan uji DMRT $\alpha=5 \%$.

\section{HASIL DAN PEMBAHASAN}

Sidik ragam menunjukkan ekstrak pelarut fosfat berpengaruh nyata sedangkan pemupukan SP-36 dan interaksinya tidak berpengaruh nyata terhadap panjang tongkol. 
Tabel 1. Panjang tongkol pada berbagai perlakuan pemupukan SP-36 dan ekstrak pelarut fosfat (EPF)

\begin{tabular}{|c|c|c|c|c|c|}
\hline \multirow{2}{*}{ EPF (liter.ha- ${ }^{1}$ ) } & \multicolumn{4}{|c|}{ Pemupukan SP-36 (kg.ha-1) } & \multirow[b]{2}{*}{ Rerata } \\
\hline & 0 & 50 & 100 & 150 & \\
\hline 0 & 11.77 & 12.73 & 13.57 & 13.77 & $12.96 \mathrm{a}$ \\
\hline 100 & 14.67 & 16.27 & 15.43 & 16.60 & $15.74 b$ \\
\hline Rerata & $13.22 \mathrm{~b}$ & $14.50 \mathrm{a}$ & $14.50 \mathrm{a}$ & $15.18 \mathrm{a}$ & $(-)$ \\
\hline
\end{tabular}

Keterangan: Angka yang diikuti oleh huruf yang sama tidak berbeda nyata pada taraf uji Duncan $\alpha=5 \%$. Tanda (-) menunjukkan tidak terdapat interaksi.

Hasil uji Duncan pada Tabel 1 menunjukkan panjang tongkol terpanjang pada perlakuan ekstrak pelarut fosfat (EPF) berbeda nyata dengan kontrol (tanpa pemberian ekstrak pelarut fofat). Hal ini menunjukkan bahwa EPF membantu merombak unsur hara $P$ yang ada di dalam tanah sehingga bisa tersedia bagi tanaman. Unsur hara $P$ dibutuhkan tanaman selain untuk memperbaiki perakaran juga dibutuhkan dalam fase reproduksi. Hal ini sejalan dengan hasil penelitian Yafizham (2003) menyatakan bahwa mikroba pelarut fosfat secara tunggal dapat meningkatkan produksi tanaman 20 sampai $73 \%$ dan secara langsung mampu meningkatkan pelarutan $P$ terikat tanah sehinga $P$ tersedia dalam tanah semakin meningkat. Sidik ragam menunjukkan ekstrak pelarut fosfat berpengaruh nyata sedangkan pemupukan SP-36 dan interaksinya tidak berpengaruh nyata terhadap diameter tongkol.

Tabel 2. Diameter tongkol pada berbagai perlakuan pemupukan SP-36 dan ekstrak pelarut fosfat (EPF)

\begin{tabular}{|c|c|c|c|c|c|}
\hline \multirow{2}{*}{ EPF (liter.ha-1 $)$} & \multicolumn{4}{|c|}{ Pemupukan SP-36 $\left(\mathrm{kg} \cdot \mathrm{ha}^{-1}\right)$} & \multirow[b]{2}{*}{ Rerata } \\
\hline & 0 & 50 & 100 & 150 & \\
\hline 0 & 3.33 & 3.47 & 3.50 & 3.67 & $3.49 \mathrm{a}$ \\
\hline 10 & 4.07 & 4.53 & 4.00 & 4.20 & $4.20 \mathrm{~b}$ \\
\hline Rerata & $3.70 \mathrm{a}$ & $4.00 \mathrm{a}$ & $3.75 \mathrm{a}$ & $3.93 \mathrm{a}$ & \\
\hline
\end{tabular}

Keterangan: Angka yang diikuti oleh huruf yang sama tidak berbeda nyata pada taraf uji Duncan $\alpha=5 \%$. Tanda (-) menunjukkan tidak terdapat interaksi.

Tabel 2 menunjukkan diameter tongkol terpanjang pada perlakuan ekstrak pelarut fosfat (EPF) berbeda nyata dengan kontrol (tanpa pemberian ekstrak pelarut fosfat). Hal ini menunjukkan bahwa mikroorganisme dalam EPF membantu merombak unsur hara $\mathrm{P}$ yang ada di dalam tanah sehingga bisa tersedia bagi tanaman. Unsur hara $\mathrm{P}$ dibutuhkan tanaman selain untuk memperbaiki perakaran juga dibutuhkan dalam fase reproduksi, termasuk memperbesar diameter buah.

Sidik ragam menunjukkan perlakuan ekstrak plarut fosfat, pupuk SP-36 dan interaksinya berpengaruh nyata. Tabel 3 menunjukkan perlakuan ekstrak pelarut fosfat dan dosis pupuk $150 \mathrm{~kg} \mathrm{SP36/ha} \mathrm{(E1P3)} \mathrm{tertinggi} \mathrm{dan} \mathrm{berbeda} \mathrm{nyata} \mathrm{dengan} \mathrm{semua}$ 
kombinasi perlakuan kecuali penggunaan ekstrak pelarut fosfat dan pemberian dosis $50 \mathrm{~kg}$ SP-36 (E1P1) dan penggunaan ekstrak pelarut fosfat dan pemberian dosis 100 kg SP-36 (E1P2). Bobot biji kering per hektar terendah pada perlakuan tanpa ekstrak pelarut fosfat dan tanpa pemberian pupuk $P$.

Tabel 3. Bobot biji kering per hektar pada berbagai perlakuan pemupukan SP-36 dan ekstrak pelarut fosfat (EPF)

\begin{tabular}{cccccc}
\hline \multirow{2}{*}{ EPF (liter.ha- ${ }^{-}$) } & \multicolumn{4}{c}{ Pemupukan SP-36 $\left(\mathrm{kg}_{\text {h. ha }}{ }^{-1}\right)$} & \multirow{2}{*}{ Rerata } \\
\cline { 2 - 5 } & 0 & 50 & 100 & 150 & \\
\hline 0 & $2.33 \mathrm{~d}$ & $2.51 \mathrm{~d}$ & $3.07 \mathrm{~cd}$ & $2.94 \mathrm{~cd}$ & 2.72 \\
10 & $3.66 \mathrm{bc}$ & $4.25 \mathrm{ab}$ & $4.03 \mathrm{ab}$ & $4.70 \mathrm{a}$ & 4.16 \\
\hline Rerata & 3.00 & 3.38 & 3.55 & 3.82 & $(+)$ \\
\hline
\end{tabular}

Keterangan: Angka yang diikuti oleh huruf yang sama tidak berbeda nyata pada taraf uji Duncan $\alpha=5 \%$. Tanda $(+)$ menunjukkan terdapat interaksi.

Tabel 3 juga menunjukkan semakin meningkat dosis pupuk SP-36 pada areal yang diberi ekstrak pelarut fosfat semakin meningkat bobot hasil biji per hektar. Hal ini disebabkan adanya mikroorganisme dalam larutan ekstrak pelarut fosfat yang dapat membantu dalam mengurai unsur $P$ dalam tanah. Sejalan dengan penelitian Dermiyati dkk. (2009) bahwa penyerapan unsur hara $P$ dalam jumlah yang tinggi menunjukkan adanya peranan dari mikroorganisme pelarut fosfat dalam melarutkan fosfat. Peranannya dapat dibuktikan dari besarnya jumlah $P$ yang terangkut oleh tanaman padi yang berkisar $21,28-30,67 \mathrm{~kg} \mathrm{ha}^{-1}$.

Ketersediaan $\mathrm{P}$ akibat pemberian pupuk bokashi yang relatif rendah berkisar antara 6,66-19,98 $\mathrm{kg} \mathrm{ha}^{-1}$ yang kemudian mampu melarutkan bentuk $\mathrm{P}$ tidak larut menjadi $P$ larut sebanyak antara 9,98-16,51 kg ha-1. Penyediaan unsur hara $P$ yang cukup bagi tanaman inilah yang menyebabkan tanaman jagung mampu berproduksi dengan baik.

Sidik ragam menunjukkan perlakuan ekstrak pelarut fosfat, pemupukan SP-36 dan interaksinya berpengaruh nyata.

Tabel 4. Efisiensi penggunaan $\mathrm{P}$ pada berbagai perlakuan pemupukan SP-36 dan ekstrak pelarut fosfat (EPF)

\begin{tabular}{cccccc}
\hline \multirow{2}{*}{ EPF $\left(\right.$ liter.ha- $\left.{ }^{-1}\right)$} & \multicolumn{4}{c}{ Pemupukan SP-36 $\left(\mathrm{kg} \cdot \mathrm{ha}^{-1}\right)$} & \multirow{2}{*}{ Rerata } \\
\cline { 2 - 5 } & 0 & 50 & 100 & 150 & \\
\hline 0 & $0.00 \mathrm{e}$ & $5.03 \mathrm{~b}$ & $3.07 \mathrm{c}$ & $1.96 \mathrm{~d}$ & 2.52 \\
10 & $0.00 \mathrm{e}$ & $8.50 \mathrm{a}$ & $4.03 \mathrm{bc}$ & $3.13 \mathrm{C}$ & 3.92 \\
\hline Rerata & 0.00 & 6.77 & 3.55 & 2.55 & $(+)$ \\
\hline
\end{tabular}

Keterangan: Angka yang diikuti oleh huruf yang sama tidak berbeda nyata pada taraf uji Duncan $\alpha=5 \%$. Tanda $(+)$ menunjukkan terdapat interaksi. 
Tabel 4 menunjukkan penggunaan ekstrak pelarut fosfat dan pupuk $P 50 \mathrm{~kg}$ SP36/ha (E1P1) tanaman menjadi lebih efisien dalam menggunakan $\mathrm{P}$ dan berbeda nyata dengan semua kombinasi perlakuan. Hal ini menunjukkan bahwa penggunaan ekstrak pelarut fosfat hanya membutuhkan sedikit tambahan pupuk $\mathrm{P}$ sudah dapat meningkatkan hasil biji jagung. Aplikasi ekstrak pelarut fosfat mengefisienkan penggunaan pupuk $\mathrm{P}$ karena unsur $\mathrm{P}$ yang terikat dalam tanah maupun yang ditambahkan terurai dengan baik dengan bantuan mikroorganisme yang ada dalam larutan ekstrak pelarut fosfat sehingga tersedia bagi tanaman. Hal ini sejalan dengan hasil penelitian Plante (2007), menyatakan bahwa mikroorganisme pelarut fosfat memainkan peranan penting dalam melarutkan bentuk-bentuk $P$ tidak larut dalam tanah.

\section{KESIMPULAN}

Aplikasi ekstrak pelarut fosfat dan pupuk SP-36 $50 \mathrm{~kg}$. ha ${ }^{-1}$ meningkatkan panjang dan diameter tongkol bobot, hasil biji kering per hektar serta efisiensi pemupukan fosfor

\section{UCAPAN TERIMA KASIH}

Penelitian ini dibiayai oleh DRPM Departemen Ristek-Dikti dalam bentuk Skim Penelitian Hibah Bersaing. Oleh karena itu kami mengucapkan terima kasih yang sebesar-besarnya kepada Pimpinan dan segenap jajaran pengelola DRPM RistekDikti, LP2S dan Dekan Fakultas Pertanian UMI dan mahasiswa atas bantuannya sehingga penelitian ini dapat terselenggara dengan lancar dan sukses.

\section{DAFTAR PUSTAKA}

Coopeland, L.W. and M.B. Mcdonald. 1985. Principles of Seed Science and Technology. Second Edition. Burger Publishing Company, Minneopolis, Minnesota, USA. $321 \mathrm{p}$.

Dermiyati, Jeni Antari, Sri Yusnaini dan Sutopo Ghani Nugroho, 2009. Perubahan Populasi Mikroroganisme Pelarut Fosfat pada Lahan Sawah dengan Sistem Pertanian Intensif menjadi Sistem Pertanian Organik Berkelanjutan. J. Tanah Trop., Vol. 14, No. 2, P: 143-148.

Hardjowigeno, S., 1992. Ilmu Tanah. Mediyatama Sarana Perkasa. Jakarta. 
Makkulawu, A.T, Sunartiningsih, Adnan, AM.,2012. Pengembangan Varietas Hibrida Jagung Pulut (Waxy Corn), Tahan Penyakit Bulai (Perenosclerospora maydis L.), Dan Toleran Kekeringan (Drought Tolerance) Memiliki Potensi Hasil Tinggi (10 T/Ha). Tim Implementasi PKPP 2012 Kementerian Riset dan Teknologi Republik Indonesia. Jakarta.

Plante, A.F. 2007. Soil biogeochemical cycling of inorganic nutrients and metals. In: Soil Microbiology, Ecology, and Biochemistry, 3rd, E.A. Paul (Ed.). Academic Press. Amsterdam, pp. 389-432.

Pratamaningtyas, S., 2011. Isolasi, Karakterisasi \& Uji Aktifitas Mikroba Fosfat dan Pengikat Nitrogen dari Mol (Mikroorganisme Lokal) Bonggol \& Batang Pisang (Musa paradisiaca). Laporan Hasil Penelitian Disertasi Doktor. Universitas Brawijaya. Malang.

Rouf, A.A., A. Zubair, D. Walangadi, M.Y. Antu dan Sukarto, 2010. Pengkajian Pemurnian Benih Jagung Pulut di Provinsi Gorontalo. Prosiding Pekan Serealia Nasional, 2010. p:117-121.

Suarni dan S. Widowati, 2005. Struktur, Komposisi, dan Nutrisi Jagung. Balai Penelitian Tanaman Serealia, Maros, dan Balai Besar Penelitian dan Pengembangan Pascapanen Pertanian, Bogor.

Subagyono, K., U. Haryati, dan S.H. Tala'ohu., 2009. Teknologi Konservasi Air pada Pertanian Lahan Kering. Jurnal Teknologi Konservasi Lahan Kering, P: 145181.

Syuryawati, Margaretha, dan Hadijah, 2010. Pengolahan Jagung Pulut Menunjang Diversifikasi Pangan dan Ekonomi Petani. Prosiding Pekan Serealia Nasional, 2010, P:619-626.

Yafizham. 2003. Aplikasi mikroba pelarut fosfat dan pupuk $P$ terhadap produksi kacang tanah pada tanah podsolik merah kuning. J. Agrotrop. VIII(1). P: 18-22. 